\title{
Ratiometric Singlet Oxygen Nano-optodes and Their Use for Monitoring Photodynamic Therapy Nanoplatforms
}

\author{
Youfu Cao', Yong-Eun Lee Koo', Sang Man Koo ${ }^{2}$ and Raoul Kopelman*1 \\ ${ }^{1}$ Department of Chemistry, University of Michigan, Ann Arbor, MI \\ 'Laboratory of Molecular Inorganic Advanced Materials, Department of Chemical Engineering, \\ Ceramic Processing Research Center, Hanyang University, Seoul, Korea
}

Received 18 May 2005; accepted 11 August 2005; published online 17 August 2005 DOI: 10.1562/2005-05-18-RA-532

\begin{abstract}
Ratiometric photonic explorers for bioanalysis with biologically localized embedding (PEBBLE) nanoprobes have been developed for singlet oxygen, using organically modified silicate (ORMOSIL) nanoparticles as the matrix. A crucial aspect of these ratiometric singlet-oxygen fluorescent probes is their minute size. The ORMOSIL nanoparticles are prepared via a sol-gel-based process and the average diameter of the resultant particles is about $160 \mathrm{~nm}$. These sensors incorporate the singletoxygen-sensitive 9,10-dimethyl anthracene as an indicator dye and a singlet-oxygen-insensitive dye, octaethylporphine, as a reference dye for ratiometric fluorescence-based analysis. We have found experimentally that these nanoprobes have much better sensitivity than does the conventional singlet-oxygen-free dye probe, anthracene-9,10-dipropionic acid disodium salt. The much longer lifetime of singlet oxygen in the ORMOSIL matrix, compared to aqueous solutions, in addition to the relatively high singlet oxygen solubility because of the highly permeable structure and the hydrophobic nature of the outer shell of the ORMOSIL nanoparticles, results in an excellent overall response to singlet oxygen. These nanoprobes have been used to monitor the singlet oxygen produced by "dynamic nanoplatforms" that were developed for photodynamic therapy. The singlet oxygen nanoprobes could potentially be used to quantify the singlet oxygen produced by macrophages.
\end{abstract}

\section{INTRODUCTION}

There are two different lowest excited singlet states of oxygen, ${ }^{1} \Sigma_{\mathrm{g}}{ }^{+}$and ${ }^{1} \Delta_{\mathrm{g}}$. The $\mathrm{O}_{2}\left({ }^{1} \Delta_{\mathrm{g}}\right)$, an oxygen molecule at its lowest excited singlet state, is commonly called singlet oxygen $\left({ }^{1} \mathrm{O}_{2}\right) .{ }^{1} \mathrm{O}_{2}$ is known as a highly reactive and metastable species that can

\footnotetext{
* To whom correspondence should be addressed; Department of Chemistry, University of Michigan, Ann Arbor, MI 48109, USA. Fax: 734-936-2778; e-mail: kopelman@umich.edu

Abbreviations: ADPA, anthracene-9,10-dipropionic acid disodium salt; DCM, dichloromethane; DMA, 9,10-dimethyl anthracene; DNP, dynamic nanoplatforms; DPIBF, 1,3-diphenylisobenzofuran; MB, methylene blue; MTMS, methyltrimethoxysilane; OEP, octaethylporphine; ORMOSIL, organically modified silicate; PAA, poly(acrylamide); PDMA, poly(decyl methacrylate); PDT, photodynamic therapy; PEBBLE, photonic explorers for bioanalysis with biologically localized embedding; PTMS, phenyltrimethoxysilane; ROS, reactive oxygen species; SEM, scanning electron microscopy.

(C) 2005 American Society for Photobiology 003I-8655/05
}

oxidize many chemical and biological substrates (1). Though not a radical (it does not have an unpaired electron) it is a reactive oxygen species (ROS) often associated with free radicals that have a strong oxidizing activity. ${ }^{1} \mathrm{O}_{2}$ is generated by input of energy such as light excitation or irradiation. Many organic dye molecules such as photofrin or methylene blue (MB) will produce singlet oxygen upon light excitation; these dye molecules are called photosensitizers and the process is called photosensitization (2).

${ }^{1} \mathrm{O}_{2}$ plays an important role in many natural photochemical and photobiological processes, such as photodegradation and aging processes. There is also much evidence that ${ }^{1} \mathrm{O}_{2}$ is a key element in the defense system of the mammalian body, being generated by phagocytes to kill invading microorganisms $(3,4)$. It is also reported that ${ }^{1} \mathrm{O}_{2}$ plays a role as an activator of gene expression (5). Reactions of ${ }^{1} \mathrm{O}_{2}$ are used in several fields, including organic synthesis, bleaching processes and the photodynamic therapy (PDT) of cancer (6,7). PDT has emerged as a promising method for overcoming some of the inherent problems in classical cancer therapies (8-12). It involves the selective delivery of photosensitizers such as photofrin to specific tumors. Singlet oxygen is widely believed to be the primary cytotoxic agent for killing the tumor cells in PDT. The theory is that upon excitation the photosensitizer produces singlet oxygen and other ROS, resulting in the in situ initiation of apoptosis in many types of tumors, with minimal systemic toxicity (13).

Because of the above-listed important roles of ${ }^{1} \mathrm{O}_{2}$, the detection of ${ }^{1} \mathrm{O}_{2}$ has drawn lots of interest. So far, singlet oxygen detection methods can be sorted into two groups: 1) physical detection, given by the most direct measurement of near-infrared luminescence of ${ }^{1} \mathrm{O}_{2}$ at $1270 \mathrm{~nm}$ and 2) chemical ${ }^{1} \mathrm{O}_{2}$ probes, to be discussed in this article.

Although many studies have been reported on the subject, it is still difficult to detect ${ }^{1} \mathrm{O}_{2}$ in biological systems, mainly because of its relatively short lifetime in aqueous solutions or biological environments (14). Even though it has been recently reported that singlet oxygen can be quite long-lived and diffuse over appreciable distances contrary to common perception (15), the lifetime of singlet oxygen in water itself or in live cells is still quite short (about $2 \mu \mathrm{s}$ ) and the solubility of singlet oxygen is very poor, the combination of which presents challenges to both the physical detection method and the naked molecular probes for singlet oxygen. The released ${ }^{1} \mathrm{O}_{2}$ produced in cells encounters an aqueous environment that results in the immediate quenching of a large fraction of the ${ }^{1} \mathrm{O}_{2}$ produced, hence reducing the emission signal below the sensitivity of detection methods. Several investigators 


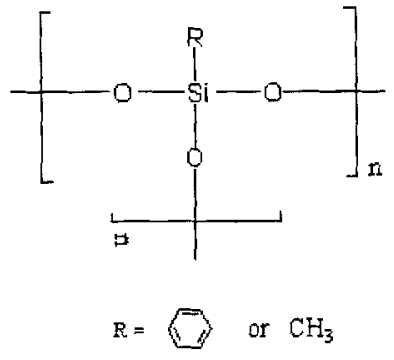

Scheme 1. Chemical structure of ORMOSIL. $R$ is the phenyl group in the inner layer of ORMOSIL and the methyl group in the outer layer of ORMOSIL.

have reported positive results from cells in suspension $(16,17)$ or from red-cell ghosts (18). There is also a recent report on timeresolved measurements of ${ }^{1} \mathrm{O}_{2}$ luminescence that was generated by PDT in cells in vitro, or in tissues in vivo (19). However, the combination of the relatively short lifetime of singlet oxygen and the very low quantum yield of singlet oxygen luminescence has either required the use of deuterium oxide $\left(D_{2} O\right)$ to increase the lifetime of ${ }^{1} \mathrm{O}_{2}$ and eliminate absorption of the 1270-nm luminescence by $\mathrm{H}_{2} \mathrm{O}$, or, alternatively, did not adequately distinguish between intracellular and extracellular ${ }^{1} \mathrm{O}_{2}$. This significantly limits the sensitivity of the physical method, thus making the detection very unreliable and irreproducible. Furthermore, it is extremely difficult for the physical method to reveal the accumulation of singlet oxygen production during the PDT process, which is one of the most important parameters to determine the efficiency of PDT.

In the chemical detection method, the ${ }^{1} \mathrm{O}_{2}$ chemical probes react with ${ }^{1} \mathrm{O}_{2}$ to produce endoperoxides, as shown in Scheme 2 . In most cases the ${ }^{1} \mathrm{O}_{2}$ chemical probes show fluorescence or absorbance peaks at certain wavelength(s), however the endoperoxides do not. Thus, by monitoring the fluorescence emission decrease of the ${ }^{1} \mathrm{O}_{2}$ chemical probes, one can monitor the singlet oxygen quantitatively. The chemical trap method is useful even when the singlet oxygen generation is very low, because the concentration of endoperoxides is proportional to the cumulative amount of singlet oxygen generated. However, most of the well-known chemical probe molecules are hydrophobic dyes that are not suitable for use in an aqueous environment. Although water-soluble derivatives of these chemical probes have been developed (20-23), the problem associated with the relatively short lifetime of ${ }^{1} \mathrm{O}_{2}$ still remains, in addition to the possible dye toxicity problem.

The combination of the chemical detection method with the photonic explorers for bioanalysis with biologically localized embedding (PEBBLE) approach promises to tackle some of the problems mentioned above. Like the other chemical methods, it is suitable for the measurement of the minute amounts of singlet oxygen produced from cells, because the concentration of endoperoxides (product of reaction between singlet oxygen and chemical probe) formed is proportional to the cumulative ${ }^{1} \mathrm{O}_{2}$ generated, thus it allows one to monitor the accumulation of singlet oxygen during the natural or PDT process. Furthermore, the PEBBLE probes can be introduced inside cells by either gene-gun delivery or liposomal delivery with negligible physical perturbation (24-26). PEBBLE technology has been used especially for intracellular measurements of biologically important ions and gas molecules (24-26). These PEBBLE-type probes have several advantages over traditional molecular dye probes: (1) the dyeembedded nanoparticles can be used in aqueous solution regardless of the hydrophobicity of the dye; (2) the dye molecule will be protected from the chemical and biological environment in the physiological system while, simultaneously, the physiological system is also protected from the potential toxicity of the dye molecules, thus enabling one to measure the concentration of the desired species in an unperturbed environment; and (3) by also loading a reference dye into the nanoparticles, ratiometric measurements can be made.

Here we developed singlet oxygen nanoprobes, designed to quantitatively monitor the singlet oxygen production during PDT, by adopting the PEBBLE technology. Organically modified silicate (ORMOSIL) nanoparticles incorporated with the hydrophobic singlet oxygen-detecting dye 9,10-dimethyl anthracene (DMA) were synthesized and tested for their feasibility as spectroscopic singlet oxygen detection probes, with very good results described below. This incorporation makes the detection take place inside the ORMOSIL particles, which significantly increases the lifetime of singlet oxygen molecules, thus allowing more time for them to react with DMA to be detected. It turns out that the incorporation of DMA inside ORMOSIL significantly enhances the sensitivity of these nanoprobes in comparison to that of the water-soluble molecular probe anthracene-9,10-dipropionic acid disodium salt (ADPA). In addition, these ORMOSIL nanoparticles are chosen as the matrix because they have been shown to provide a near-perfect environment for oxygen measurements (26) because of their good solubility, permeability and homogeneity to oxygen molecules. We thus expect that this matrix will provide similar advantages for singlet oxygen measurements, specifically the partition advantage for singlet oxygen in ORMOSIL rather than in water. Furthermore, these ORMOSIL nanoparticles can load either hydrophobic or hydrophilic dye molecules and this provides flexibility when it comes to which dyes should be chosen for optimal fabrications. We also incorporated DMA into poly (decyl methacrylate) (PDMA) nanoparticles and these nanoprobes demonstrated good responses to singlet oxygen. However, because of the severe aggregation of PDMA particles in aqueous solution, we concentrated our efforts on the ORMOSIL nanoparticles.

DMA was chosen as the chemical trap mainly because it has a relatively high quenching rate constant and unique selectivity for ${ }^{1} \mathrm{O}_{2}$ ( $\mathrm{k}$ is $9.1 \times 10^{8} \mathrm{M}^{-1} \mathrm{~s}^{-1}$ for DMA quenching of singlet oxygen) (27). In addition, the fluorescence of DMA does not change upon contact with hydrogen peroxide, nitric oxide or superoxide, confirming the specificity of DMA for ${ }^{\prime} \mathrm{O}_{2}$ (27). 1,3-Diphenylisobenzofuran (DPIBF) is traditionally considered to have the fastest reaction rate constant with singlet oxygen $\left(9.6 \times 10^{8} M^{-1} \mathrm{~s}^{-1}\right)$; however, it suffers from a severe auto-oxidation problem, especially in water (K. Gwangseong, Y. Cao, Y. E. Koo. W. Tang and $\mathrm{R}$. Kopelman, in preparation), therefore it was not chosen as the probes in this paper. DMA reacts with ${ }^{i} \mathrm{O}_{2}$ to produce DMAendoperoxide, as shown in Scheme 1. As for DMA endoperoxide, it is quite thermally stable; it must be heated to about $120^{\circ} \mathrm{C}$ to dissociate into DMA and oxygen molecules $(28,29)$. Thus the reaction of DMA with singlet oxygen to produce DMA endoperoxide is irreversible under our experimental conditions, which is conducive to singlet oxygen detection. We also believe that the physical quenching of singlet oxygen by DMA is relatively small, as is the case for similar probes like ADPA or diphenyl anthracene (DPA), and that it is negligible when compared to the overall quenching by the solvent (30). DMA also has a strong fluorescence emission in the range of $400-450 \mathrm{~nm}$, whereas DMA-endoperoxide has no emission in that range. Thus by monitoring the fluorescence 
decrease of DMA, one can detect the amount of singlet oxygen produced over time. For ratiometric measurement, the octaethylporphine (OEP) dye was incorporated into the ORMOSIL nanoparticles, because of its relatively low reaction rate with ${ }^{1} \mathrm{O}_{2}$. Both reference and probe molecules are hydrophobic but the nanoprobes containing them are easily suspended in water, as required for the measurement of singlet oxygen production in an aqueous environment. The previously used ADPA molecules (30) are inferior in their kinetic and spectroscopic parameters compared to DMA, but were developed to have the advantage of being water soluble compared to DMA and other similar anthracene derivatives. The PEBBLE combines the advantages of both systems. In the work described below, ORMOSIL nanoprobes have been used to successfully determine the singlet oxygen production efficiency of photosensitizer-loaded PDT nanoplatforms designed and developed in our lab (31-33).

Intracellular measurements of ${ }^{1} \mathrm{O}_{2}$ produced during phagocytosis were reported by Steinbeck et al. (3), where they used micron-sized glass beads coated with 9,10-diphenyl anthracene, with perylene coated glass beads as an internal standard. Although they successfully demonstrated that ${ }^{1} \mathrm{O}_{2}$ is produced from the cells, there are still aspects to be improved: (1) Because the dye is coated onto the surface of the glass beads, and hence exposed to the cells directly, dye toxicity may affect the cells. (2) The glass bead size was $1.6 \mu M$, which may be large enough to perturb the cells. We note that our singlet oxygen nanoprobes contain the dye inside the nanoparticles, avoiding the toxicity problem caused by the dye molecule; also, the probe size is reduced to $1 / 10$ the size of the glass bead, i.e. the perturbing volume is reduced by a factor of 1000. We thus believe that these nanoprobes are promising candidates for intracellular singlet oxygen measurements, such as the singlet oxygen production inside live macrophages.

\section{MATERIALS AND METHODS}

Chemicals. Phenyltrimethoxysilane (PTMS), methyltrimethoxysilane (MTMS), ammonia, 9,10-dimethyl anthracene (DMA), methylene blue (MB), and dichloromethane (DCM) were obtained from Aldrich (Milwaukee, WI) and used without further purification. Octaethylporphine (OEP) was purchased from Frontier Scientific, Inc. (Logan, UT). Anthracene-9,10-dipropionic acid, disodium salt (ADPA) was purchased from Molecular Probes (Eugene, OR). A stock solution of $10 \mu M$ ADPA was made in water and kept in the dark until use. The chemicals for the synthesis of photofrinloaded Poly(acrylamide) (PAA) nanoparticles including hexane, Aerosol OT, and brij 30, acrylamide, 3-Aminopropyl-methacrylamide, N, NMethylene(bis)acrylamide, 10\% APS and TEMED were purchased from Aldrich (Milwaukee, WI). Photofrin was a gift from Axcan Pharmaceuticals (Mont Saint-Hilaire, Quebec, Canada). The $18 \mathrm{M} \Omega$ water used for all the solutions was purified by a Barnstead 1 Thermolyne Nanopure II system.

Gases. $\mathrm{O}_{2}\left(99.6 \%\right.$, extra-dry grade), air (dry grade), $\mathrm{N}_{2}(99.998 \%$, prepurified) and Argon ( $99.7 \%$, prepurified) were obtained from Cryogenic Gases (Detroit, MI). Nitric oxide (99.9\%, CP grade) was obtained from Matheson Tri-Gas (Montgomeryville, PA).

\section{Experimental sections}

Preparation of ORMOSIL nanoparticles incorporated with DMA or OEP. Two different batches of ORMOSL particles were prepared exactly as described in our previous work (25): one batch was loaded with DMA and the other was loaded with OEP. The dye amounts used in each batch were as follows: for DMA-loaded PEBBLE, $0.6 \mathrm{~mL}$ of DMA $(1 \mathrm{mg} / \mathrm{mL}$ in DCM); and for OEP-loaded ORMOSIL PEBBLE, $0.5 \mathrm{~mL}$ of OEP (1 mg/ $\mathrm{mL}$ in DCM). The resulting two batches of ORMOSIL PEBBLE were suction-filtered through a Fisher-brand glass microanalysis vacuum filter holder with a $0.1-\mu \mathrm{m}$ Osmonics/MSI MAGNA nylon membrane filter. The PEBBLE were rinsed three times with water and then resuspended in the<smiles>Cc1c2ccccc2c(C)c2cc([O+]=O)ccc12</smiles>

9, 10-Dime thyl Anthracene

Endoperoxide

Scheme 2. The reaction of DMA and singlet oxygen.

water-ethanol 1:2 mixture, sonicated for $5 \mathrm{~min}$ and then filtered through a $0.02-\mu M$ Whatman Anodisc filter membrane, washed with ethanol and allowed to air-dry. Emission spectra of $0.1 \mathrm{mg} / \mathrm{mL}$ of these two batches of PEBBLE in 50:50 water/ethanol were taken on fluorimeter. Every one part of DMA-loaded ORMOSIL powder was mixed together with two parts of OEP-loaded ORMOSL powder. This mixed powder was the ratiometric singlet oxygen nanoprobe and, unless noted otherwise, was used throughout all the experiments described in this paper.

Synthesis of amine-functionalized photofrin-incorporated PAA nanoparticles. A clean $250-\mathrm{mL}$ round-bottom flask was charged with argonpurged hexanes. Aerosol OT ( $3.2 \mathrm{~g})$ and brij $30(6.4 \mathrm{~mL})$ were added to the reaction flask and the contents were stirred under argon atmosphere until a uniform solution resulted. A 20-mL glass sample tube was charged with acrylamide $(1.1 \mathrm{~g})$ and $0.1 \mathrm{M}$ sodium phosphate buffer $(4 \mathrm{~mL}, \mathrm{pH} 7.25)$ and sonicated $10 \mathrm{~min}$ to yield a uniform solution. 3-Aminopropyl-methacrylamide $(0.2 \mathrm{~g})$ was added to the acrylamide solution and sonication was continued until a clear solution formed. N, N-Methylene(bis) acrylamide $(0.36 \mathrm{~g})$ was added to the acrylamide solution and sonicated again until a clear solution resulted. Photofrin $(20 \mathrm{mg}$, Axcan Pharmaceuticals) was added to the acrylamide solution and sonicated for a period of $20 \mathrm{~min}$ at room temperature. The clear, dark red monomer solution was added to the hexane reaction mixture and stirred vigorously for $20 \mathrm{~min}$ at room temperature. Ten percent APS $(65 \mu \mathrm{L})$ and TEMED $(85 \mu \mathrm{L})$ were added to the reaction mixture under argon atmosphere. The reaction mixture was gently stirred at room temperature in the dark for $24 \mathrm{~h}$. The reaction mixture was concentrated to a thick liquid residue and the residue was diluted with $100 \mathrm{~mL}$ of ethanol. The mixture was sonicated for $2 \mathrm{~min}$ and the separated particles were washed in an amicon stirred cell (Millipore, $200 \mathrm{~mL}$ ) with ethanol $(5 \times 180 \mathrm{~mL})$. The deep brown nanoparticles were further dried under nitrogen atmosphere and gently crushed to a fine powder. The material was covered with aluminum foil to protect it from light and stored in the refrigerator at $4^{\circ} \mathrm{C}$.

Scanning electron microscopy (SEM) imaging. The above two individual batches of ORMOSIL PEBBLE were dispersed in 50:50 water/ethanol and sonicated for $20 \mathrm{~min}$ to prevent aggregation of particles. Then a drop of the PEBBLE solution was placed on the SEM specimen mount (aluminum) and dried gradually at room temperature. The sample was then sputter-coated with gold and the SEM images were taken on the Phillips XL30 Scanning Electron Microscope.

Optics. All fluorescence emission spectra are taken on a FluoroMax-2 spectrofluorimeter (ISA Jobin Yvon-Spex, Edison, NJ), slits set to $5 \mathrm{~nm}$ for excitation and $5 \mathrm{~nm}$ for emission respectively. If without any further specification, all emission spectra are taken with excitation at $380 \mathrm{~nm}$. Without any further specification, all experiments and spectra were done in a darkroom with the lights off, because the photosensitizers used in this paper are sensitive to room light.

Detection of singlet oxygen produced by free $M B$ in distilled water. To detect the singlet oxygen production by the photosensitizers (MB or photofrin), the ORMOSIL nanoprobes' suspension was mixed with certain amount of photosensitizer solution. The mixture was then irradiated continuously at $650 \mathrm{~nm}$ (for $\mathrm{MB}$ ) or $630 \mathrm{~nm}$ (for photofrin) for a fixed amount of time; after each irradiation, the emission spectrum of the mixture was taken. By monitoring the emission spectra over the irradiation time, it is possible to monitor the singlet oxygen production.

Singlet oxygen was produced using $10 \mu M \mathrm{MB}$ in distilled water. Based on the excitation and absorption spectra of $\mathrm{MB}$ in water, a 650 -nm light source was used to irradiate the mixed suspension to produce singlet oxygen. Two milligrams of the above-mixed ORMOSIL PEBBLE was suspended in $10 \mathrm{~mL}$ of distilled water. Then, $0.5 \mathrm{~mL}$ of the suspension was mixed with $2 \mathrm{~mL}$ of $10 \mu \mathrm{MMB}$ in distilled water inside a quartz cell. Three 
a

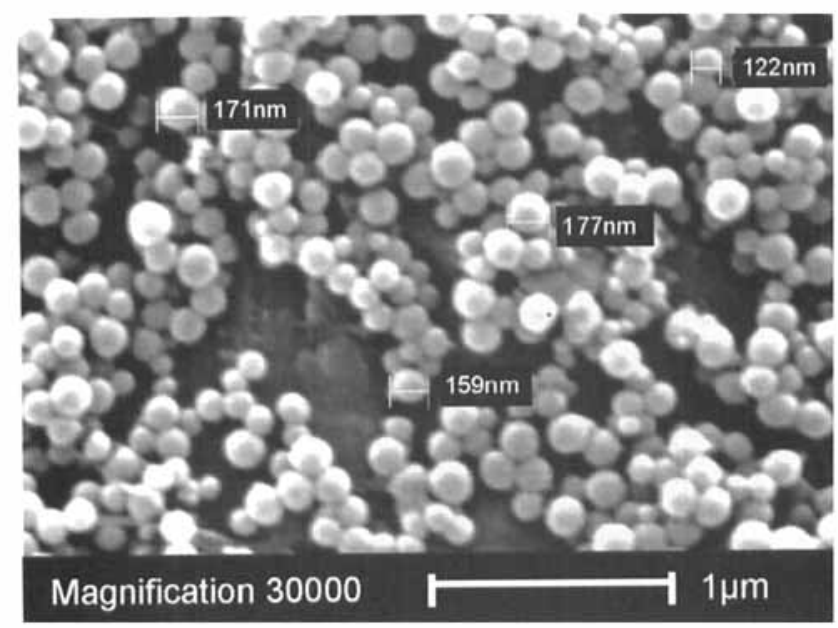

b

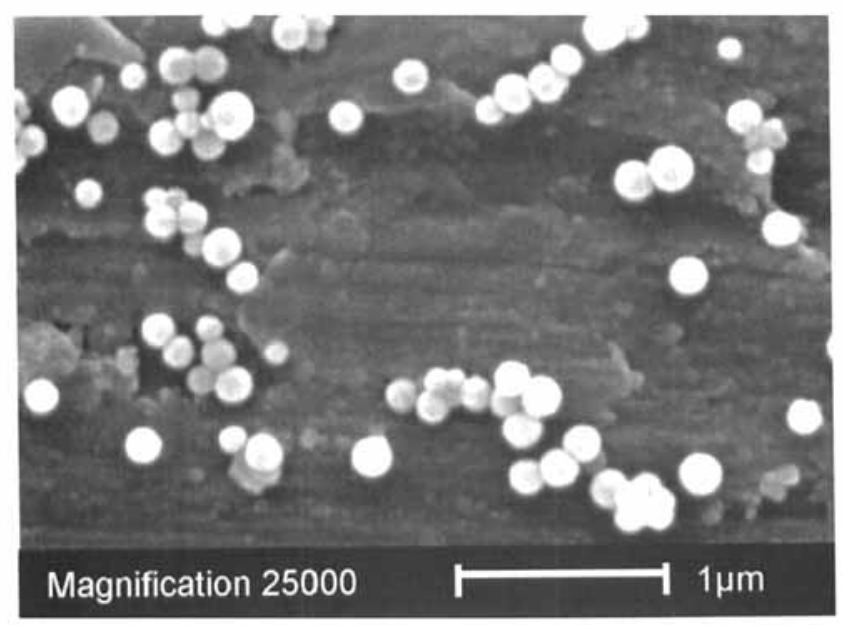

Figure 1. SEM images of ORMOSIL PEBRLE: (a) DMA-loaded particles; (b) OEP-loaded particles. The average diameter of the particles is about $160 \mathrm{~nm}$.

emission spectra of this mixed sample were taken on the fluorometer immediately following the mixing. The sample was then illuminated at $650 \mathrm{~nm}$ (with five 5-nm excitation/emission slit widths) for $1 \mathrm{~min}, 2 \mathrm{~min}$, $3 \mathrm{~min}, 10 \mathrm{~min}, 20 \mathrm{~min}$ and $40 \mathrm{~min}$ respectively; three emission spectra were taken right after each irradiation. The average of the three emission spectra represents each irradiation.

To check the photobleaching of MB in distilled water under the same experimental condition, $2.5 \mathrm{~mL}$ of $10 \mu M \mathrm{MB}$ in distilled water was continually irradiated at $650 \mathrm{~nm}$ for up to $40 \mathrm{~min}$ and emission spectra were taken to monitor the emission intensity changes.

Auto-oxidation and control tests. The above ORMOSIL PEBBLE suspension was measured into $0.5-\mathrm{mL}$ samples and mixed with $2 \mathrm{~mL}$ of distilled water. The samples were irradiated for $0 \mathrm{~min}, 1 \mathrm{~min}, 3 \mathrm{~min}, 5 \mathrm{~min}$, $10 \mathrm{~min}, 20 \mathrm{~min}$, and $40 \mathrm{~min}$ respectively and three emission spectra were taken after each irradiation.

Another $0.5 \mathrm{~mL}$ of the above PEBBLE suspension was mixed with $2 \mathrm{~mL}$ of $10 \mu M$ of MB in distilled water inside the quartz cell. The sample was then put in the darkness and three emission spectra were taken after 0 min, $1 \mathrm{~min}, 3 \mathrm{~min}, 5 \mathrm{~min}, 10 \mathrm{~min}, 20 \mathrm{~min}$ and $40 \mathrm{~min}$, respectively.

Detection of singlet oxygen produced by free $M B$ or $M B$ incorporated inside PAA nanoparticles. To compare the performance between these ORMOSIL nanoprobes and free dye probes ADPA, samples A and B were prepared.
MB was incorporated inside PAA nanoparticles and the concentration of MB inside was measured by absorption calibration to be $1 \times 10^{-4} \mathrm{mg} / \mathrm{mg}$ (30). Ten milligrams of this sample was suspended in $10 \mathrm{~mL}$ of distilled water. Two milliliters of this suspension was mixed with $0.5 \mathrm{~mL}$ of the above-described ORMOSIL nanoprobes suspension to form sample A.

To make sample B, $1 \times 10^{-3} \mathrm{mg} \mathrm{MB}$ was dissolved in $10 \mathrm{~mL}$ of distilled water and mixed with $10 \mathrm{mg}$ of blank PAA particles, thus making a final concentration of MB of $1 \times 10^{-4} \mathrm{mg} / \mathrm{mg}$. This mixture was sonicated for about $15 \mathrm{~min}$. Two milliliters of this suspension was then mixed with $0.5 \mathrm{~mL}$ of above ORMOSIL singlet oxygen nanoprobes, forming sample B.

For both samples $\mathrm{A}$ and $\mathbf{B}$, three emission spectra were taken after $0 \mathrm{~min}$, $1 \mathrm{~min}, 2 \mathrm{~min}, 5 \mathrm{~min}$ and $20 \mathrm{~min}$ of irradiation at $650 \mathrm{~nm}$ respectively. The same experiment was done using $10 \mu M$ ADPA in distilled water as the singlet oxygen detector, instead of the ratiometric ORMOSIL nanoprobes.

Detection of singlet oxygen produced by photofrin-incorporated PAA nanoparticles. In this experiment, the above-synthesized amine-functionalized photofrin-incorporated modified PAA particles were used as singlet oxygen source. Because the emission of photofrin overlaps with OEP, only DMA-loaded ORMOSIL nanoparticles were used as the singlet oxygen probes. Two milligrams of DMA ORMOSIL particles were suspended in $10 \mathrm{~mL}$ of distilled water. A $0.5-\mathrm{mL}$ portion of this suspension was mixed with $2 \mathrm{~mL}$ of $0.1 \mathrm{mg} / \mathrm{mL}$ photofrin-incorporated PAA in distilled water. The mixed suspension was irradiated at $630 \mathrm{~nm}$ for $0 \mathrm{~min}, 1 \mathrm{~min}, 3 \mathrm{~min}$, $5 \mathrm{~min}, 10 \mathrm{~min}, 15 \mathrm{~min}$ and $30 \mathrm{~min}$, respectively. After each irradiation, three emission spectra were taken, with excitation and irradiation slit widths set as $5 \mathrm{~nm}$ and emission slit width set as $2 \mathrm{~nm}$.

Exactly the same experiments were done using $10 \mu M$ ADPA in distilled water as the singlet oxygen probe.

To correlate the relationship between the amount of singlet oxygen produced and the concentration of the photosensitizer, the following experiments were designed.

The above amine-functionalized photofrin-incorporated PAA nanoparticles were suspended in distilled water with two different concentrations: one at $1 \mathrm{mg} / \mathrm{mL}$, the other at $0.25 \mathrm{mg} / \mathrm{mL}$. A $2-\mathrm{mL}$ portion of each of these two suspensions was mixed individually with $0.5 \mathrm{~mL}$ of the above singlet oxygen nanoprobes. Each mixed suspension was irradiated at $630 \mathrm{~nm}$ for up to $30 \mathrm{~min}$. The emission spectra of the samples were monitored at different time intervals.

Leaching and photobleaching. The leaching test was performed by preparing a $0.2 \mathrm{mg} / \mathrm{mL}$ PEBBLE solution in distilled water and monitoring the fluorescence of the filtrate (filtered with a $20 \mathrm{~nm}$ Whatman cellulose membrane), every $2 \mathrm{~h}$ over a period of 3 days.

A photobleaching test of these PEBBLE samples was also performed to evaluate the accuracy and lifetime of the singlet oxygen nanoprobes. The same $0.2 \mathrm{mg} / \mathrm{mL}$ PEBBLE suspension in water was prepared and $3 \mathrm{~mL}$ of this suspension was placed in a quartz optical cell. The sample was continuously irradiated at $380 \mathrm{~nm}$ (excitation for DMA) and $630 / 650 \mathrm{~nm}$ (excitation for Photofrin/MB), with the excitation slit width set at $10 \mathrm{~nm}$. The peak intensities at $424 \mathrm{~nm}$ (from DMA) and $621 \mathrm{~nm}$ (from OEP) were monitored over a period of $30 \mathrm{~min}$.

Interference of oxygen and nitric oxide (NO). Two milligrams of the mixed ORMOSIL powder was suspended in $10 \mathrm{~mL}$ of distilled water and sonicated for about $30 \mathrm{~min}$. A 3-mL portion of the suspension was then transferred into an adjustable airtight quartz cell capped with Teflon. A 4inch hypodermic needle was inserted to transfer gas into the solution inside the quartz cell, and another 1.5 -inch needle was used for ventilation. For the oxygen interference test, a combination of cylinders of pure nitrogen and oxygen and gas blender (Cole Parmer Instrument Co., Vernon Hills, IL) was used to achieve precise gas mixtures that were passed at selected flow rates. The interference from NO was tested by repeatedly purging the PEBBLE suspension first with nitrogen, second with NO and then with nitrogen again, and so on. The type of NO used was $99.9 \%$ NO. The time to bubble the mixed gas through the solution for each measurement was about $10 \mathrm{~min}$, enough time to reach the distribution equilibrium. Emission spectra were taken immediately after each purging with air, oxygen, nitrogen and NO respectively.

\section{RESULTS AND DISCUSSION}

\section{ORMOSIL particles}

The morphology of the dye-incorporated MTMS/PTMS nanoparticles was determined by SEM. Figure 1 shows typical 
monodispersed spherical ORMOSIL PEBBLE. They have an average diameter of about $160 \mathrm{~nm}$.

\section{Mixing DMA and OEP ORMOSIL PEBBLE for ratiometric analysis}

Many chemical probes do not have reference signals. However, for previous PEBBLE nanosensors in this lab there was an attempt to introduce the reference dye into the PEBBLE so as to make it ratiometric, i.e. to minimize such effects as excitation light-intensity fluctuation or sample-size fluctuation, thus making the detection more reproducible and reliable. Therefore, historically each PEBBLE nanosensor/nanoprobe contained both sensing and reference dye molecules (24-26). However, attempts to load both dyes simultaneously resulted in loading inconsistency, presumably because of solubility and/or energy transfer. After many frustrating trials of mixing different molar ratios of OEP and DMA to get reasonably similar intensities of emission out of both DMA and OEP, a different approach was taken to overcome this problem. A batch of DMA-incorporated ORMOSIL PEBBLE was prepared, then a batch of OEP-incorporated ORMOSIL PEBBLE was prepared, then two different batches of PEBBLE were mixed at various ratios to reach the goal. The advantages of this approach are as follows:

1. It still fits the ratiometric scheme.

2. Instead of incorporating both sensing and reference dyes at the same time, which usually causes added complications for the synthesis of the nanoparticles, doping one at a time makes the synthesis easier.

3. It makes it easier to adjust the ratios between sensing and reference dyes. Instead of preparing new batches of PEBBLE for each ratio of sensing and reference dyes and repeatedly adjusting the ratios, which is usually very timeconsuming (especially true for PEBBLE preparation, where the average time of preparing a batch of PEBBLE is $24 \mathrm{~h}$ ) and expensive (especially if the dyes involved are expensive) one can just mix different amounts of two different batches of PEBBLE at one's will.

4. It minimizes energy transfer between indicator and reference dyes, which is usually a major concern in terms of choosing sensing and reference dyes that are shared by the same PEBBLE.

What should be noted here is that this approach is based on the assumption that two different batches of PEBBLE are monodispersed and homogeneous (when mixed and suspended in the solvent). This assumption is usually true if the two batches of PEBBLE have the same matrix, but it could also work with different matrixes. As stated, this new approach also provides more flexibility in terms of choosing sensing and reference dyes. However, one potential problem with this approach is that, for cell measurements, and whenever the local area of interest is small, it is still necessary for the mixed particles to be monodispersed and homogenously distributed.

Based on the emission spectra of two different batches of DMA(emission peaks: $408 \mathrm{~nm}, 430 \mathrm{~nm}$ and $456 \mathrm{~nm}$ ) or OEP- (621 nm) loaded ORMOSIL particles, every one part of DMA ORMOSIL nanoparticles was mixed with two parts of OEP ORMOSIL nanoparticles so that the emission peak intensity of DMA would be about the same as that of OEP after the singlet oxygen measurement (a 40-50\% signal decrease of DMA during the measurement was taken into account). Without any other specification, these

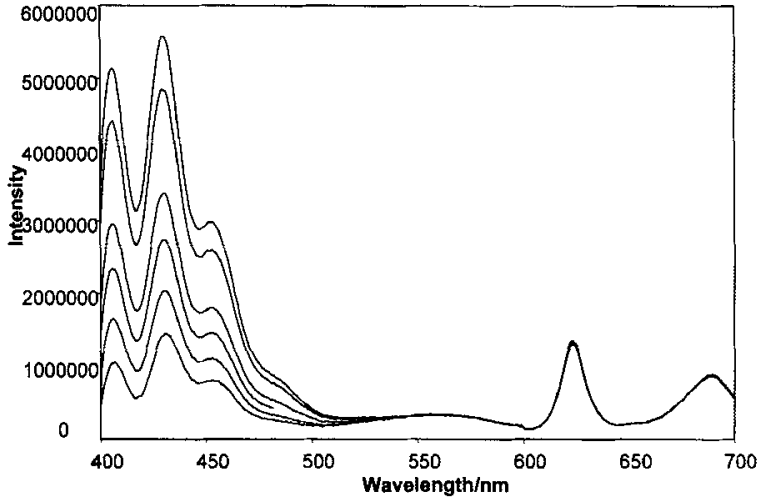

Figure 2. Detection of singlet oxygen produced by $10 \mu M \mathrm{MB}$ in distilled water with DMA-loaded ORMOSIL singlet oxygen nanoprobes. Accumu-

same mixed DMA/OEP ORMOSIL nanoparticles were used for all of the singlet oxygen measurements.

\section{Detection of singlet oxygen released by free MB in distilled water}

One of the traditional photosensitizers that have been used for a variety of applications, including PDT, is MB; its high quantum yield for ${ }^{1} \mathrm{O}_{2}$ generation $(\Phi \Delta \sim 0.5)$ in the therapeutic window $(600-900 \mathrm{~nm})$, coupled with its low toxicity, has led to the testing of MB as a promising candidate for PDT of cancer (34-35). It is also inexpensive and it is FDA-approved for ethemoglobinemia. Therefore MB has been chosen in this paper as one of the primary photosensitizers, i.e. as singlet oxygen source.

Regarding Fig. 2, it should be noted that the emission of DMA decreases more dramatically at the beginning of the irradiation. After 40 min irradiation, about 73\% DMA emission signal reduction was observed, which means that about $73 \%$ of the DMA molecules had reacted with singlet oxygen to form DMA endoperoxides. On the other hand, the emission of OEP stays almost constant during the entire irradiation process, up to $40 \mathrm{~min}$. Based on Fig. 2, one can figure out that $\mathrm{k}_{\mathrm{DMA}} / \mathrm{k}_{\mathrm{OEP}}$, the singlet oxygen quenching rate constant ratio between DMA and OEP, which is at least 100 (a lower order of magnitude limit). This confirms OEP's role as a very good reference dye for these nanoprobes.

To make sure that the emission signal decrease of DMA is indeed induced by singlet oxygen, control autooxidation and other blank tests were done and the results are shown in Figs. 3 and 4. Compared with Fig. 2's setup, Fig. 3's setup is the same, except that there is no MB inside the mixture. Fig. 3 shows that irradiation with 650 -nm light causes very little signal change where there are no MB molecules in the mixture. In Fig. 4's setup, everything stays the same as in Fig. 2, (including MB), except that there is no 650$\mathrm{nm}$ light irradiation.

A photobleaching test of MB under exactly the same experimental conditions reveals less than $1 \%$ signal loss over 40 min irradiation. Combining the messages of Figs. 2, 3 and 4, a reasonable conclusion is that the observed DMA signal decrease could only be caused by the simultaneous presence of both the 650$\mathrm{nm}$ irradiation and the presence of MB. Neither irradiation nor MB by itself could be responsible for this behavior. Furthermore, the aromatic hydrocarbons have been known to have a specific 


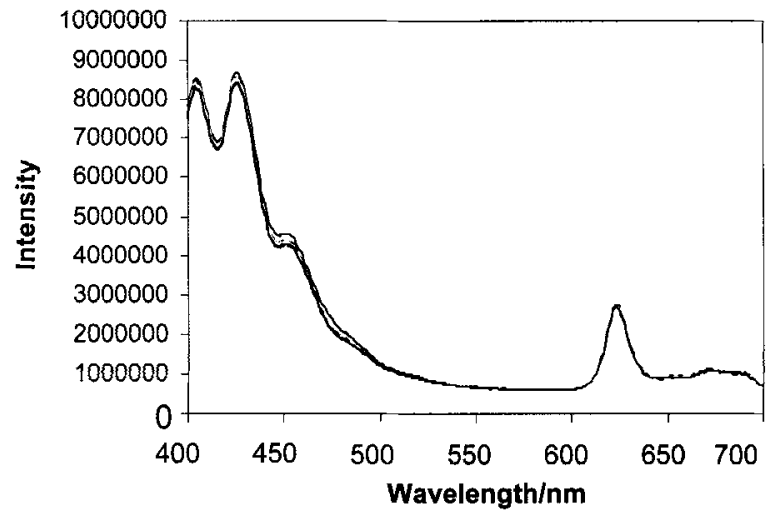

Figure 3. Control 1: Emission spectra (excited at $380 \mathrm{~nm}$ ) of $0.5 \mathrm{~mL}$ of the above DMA ORMOSIL PEBBLE suspension, mixed with $2 \mathrm{~mL}$ of distilled water. No MB was added. The irradiation is at $650 \mathrm{~nm}$ for specified time. Accumulated irradiation time (from top to bottom): $0 \mathrm{~min}, 1 \mathrm{~min}$, $3 \mathrm{~min}, 5 \mathrm{~min}, 10 \mathrm{~min}, 20 \mathrm{~min}$ and $40 \mathrm{~min}$, respectively.

reactivity toward singlet oxygen because of the electrophilic nature of singlet oxygen and such selectivity over other chemical entities has been reported (36). In the case of some of the very reactive singlet oxygen acceptors such as DPIBF, however, auto-oxidation by ground state oxygen was observed. We did oxygen and nitrogen flow-through tests to check the contribution of $\mathrm{O} 2 / \mathrm{N} 2$ on the emission signal decrease of DMA and it turns out to be negative. Additionally, our preliminary results (Y. Koo and R. Kopelman, in preparation) show that other ROS, such as hydroxyl radical or superoxide, barely diffuse into the ORMOSIL nanoparticles. The combination of the above points indicates that the DMA signal decrease is indeed caused by the production of singlet oxygen. This tends to confirm that the singlet oxygen produced by photoirradiation is mainly responsible for the fluorescence emission decrease of DMA.

If one could figure out the concentrations of DMA inside the ORMOSIL matrix before and after the exposure to the singlet oxygen, the absolute amount/concentration of singlet oxygen could be determined, based on the molar ratio of 1:1 between endoperoxide and singlet oxygen and the assumption that the emission intensity of DMA is proportional to the concentration of DMA. This approach turns out to be ideal for the detection of intracellular singlet oxygen production $(3,4)$.

Another analytical approach for singlet oxygen detection by chemical probe is to use the kinetics model proposed by Moreno et al. (30). Based on the model, one gets

$$
[\mathrm{DMA}]=[\mathrm{DMA}]_{\mathrm{t}=0} \cdot \exp (-\mathbf{k} \cdot \mathbf{t})
$$

And $k=\Phi^{102} k_{2} I^{\text {abs }} / k_{1}$, with the assumption of $k_{1} \gg k_{2} \cdot[D M A]$, where $k_{1}$ is the singlet oxygen solvent quenching rate constant and $k_{2}$ is the reaction rate constant of DMA with singlet oxygen in ORMOSIL. Both $k_{1}$ and $k_{2}$ may be affected by the ORMOSIL matrices. Because of the fact that the bulk of the suspension is water, with only a relatively small portion of the volume taken up by ORMOSIL nanoparticles, and the singlet oxygen molecules are mostly produced in water and have to diffuse through the water to get into the ORMOSIL matrices to be detected, we use the $k_{1}$ value for water, which is $3 \times 10^{5} \mathrm{~s}^{-1}(37)$. The $\mathrm{k}_{2}$ value will be slightly different from that in water because the ORMOSIL matrices affect the lifetime and the solubility of ${ }^{1} \mathrm{O}_{2}$ as described in the comparison with free ADPA part below. The matrix effects are under further study and preliminary results showed that the high $\mathrm{k}_{2}$

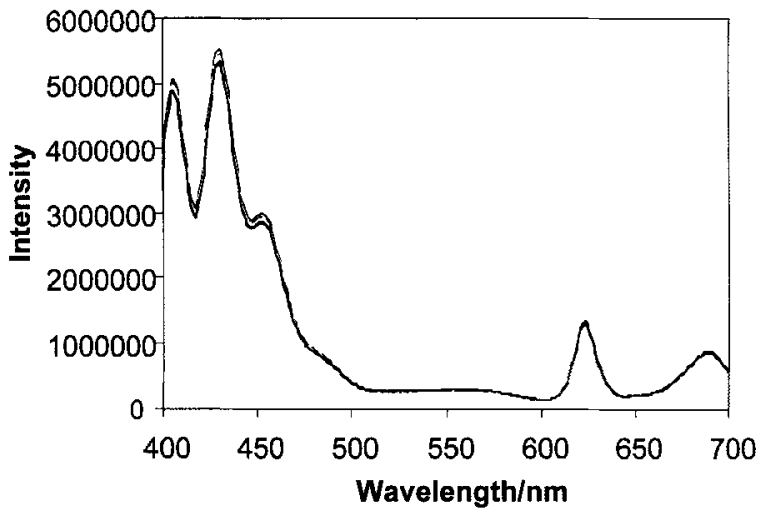

Figure 4. Control 2: Emission spectra (excited at $380 \mathrm{~nm}$ ) of $0.5 \mathrm{~mL}$ of the ORMOSIL PEBBLE suspension mixed with $10 \mu M \mathrm{MB}$ in distilled water, without $650 \mathrm{~nm}$ irradiation. Accumulated irradiation time (from top to bottom): $0 \mathrm{~min}, 1 \mathrm{~min}, 3 \mathrm{~min}, 5 \mathrm{~min}, 10 \mathrm{~min}, 20 \mathrm{~min}$ and $40 \mathrm{~min}$, respectively.

value of DMA in water was maintained in ORMOSIL matrices $(K$. Gwangseong, Y. Cao, Y. E. Koo. W. Tang and R. Kopelman, in preparation). If we approximate the $\mathrm{k}_{2}$ value as $9.1 \times 10^{8} \mathrm{M}^{-1} \mathrm{~s}^{-1}$, the value for DMA reacting with singlet oxygen in water (27) and the DMA concentration in the tested solution is estimated to be around $10^{-7} M$, based on the number of dye molecules added during the synthesis, the experimental condition for this work meets the assumption made above.

With the caveat that the fluorescence intensity of DMA is proportional to the concentration of DMA, one can plot the semilog of the peak ratios of DMA/OEP against time and thus obtain the $\mathrm{k}$ value for each irradiation case. We note that indeed the fluorescence of the DMA free-dye was found to vary linearly with that of the concentration below $10^{-6} M$ (data not shown). These $\mathrm{k}$ values can be used for quality control of singlet oxygen production by the same PDT agents when tested with the same amount of PS. Still, it cannot be applied for comparing different PS values. However, one needs to note here that the $\mathrm{k}$ value by itself cannot be directly used to determine the absolute amount of singlet oxygen detected or produced. Therefore our approach in this work is to compare the relative $\mathbf{k}$ values for different experimental situations, where only one parameter is varied. This approach has been used to compare the singlet oxygen production efficiency by MB when the same amount of MB is either dissolved in distilled water or incorporated in PAA nanoparticles.

\section{Comparisons between ratiometric ORMOSIL nanoprobes and free dye probe ADPA}

As described in the experimental sections, two sets of independent experiments have been done to compare the performances of these ORMOSIL nanoprobes and free-dye ADPA probes. ADPA and DMA are quite similar to each other in terms of chromophore structures, fluorescence quantum yield, excitation/absorption/ emission spectra and the reaction rate constant $\left(\mathrm{k}\right.$ is $1 \times 10^{8} M^{-1}$ $\mathrm{s}^{-1}$ for ADPA in water) (30), which makes the comparison easier and more straightforward.

In the experimental setups of Figs. 5 and 6, all conditions are the same except that in Fig. $5,1 \times 10^{-4} \mathrm{mg} / \mathrm{mL}$ free MB molecules in distilled water are irradiated at $650 \mathrm{~nm}$ to release singlet oxygen whereas in Fig. 6, the same number of $\mathrm{MB}$ molecules are incorporated inside PAA particles. When Figs. 5 and 6 are 


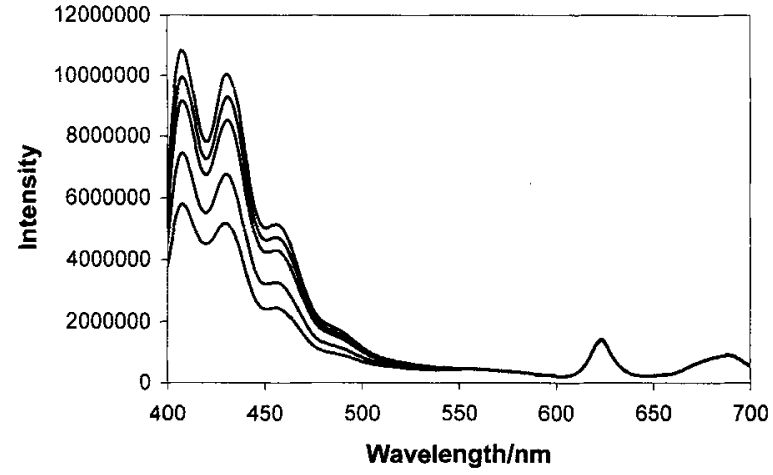

Figure 5. Emission spectra (excited at $380 \mathrm{~nm}$ ) of $1 \times 10^{-4} \mathrm{mg} / \mathrm{mL}$ of free $\mathrm{MB}$ in distilled water and DMA ORMOSIL nanoprobes upon light illumination at $650 \mathrm{~nm}$. The same quantity of blank PAA nanoparticles (as in Fig. 6) was added to the free-dye mixture to minimize the light scattering interference caused by the PAA nanoparticles. Accumulated irradiation time (from top to bottom): $0 \mathrm{~min}, 1 \mathrm{~min}, 2 \mathrm{~min}, 5 \mathrm{~min}$ and $20 \mathrm{~min}$, respectively.

compared, as shown in Fig. 7, the $\mathrm{k}$ value for the free-MB dye case is $0.0005\left(\mathrm{~s}^{-1}\right)$ whereas it is $0.0002\left(\mathrm{~s}^{-1}\right)$ for the same amount of MB dyes incorporated inside PAA particles. This tells us that about $150 \%$ more singlet oxygen is detected by the DMA ORMOSIL nanoprobes in the first $5 \mathrm{~min}$ for the sample of free $\mathrm{MB}$ molecules than when the same number of dye molecules are incorporated inside PAA particles (both samples are irradiated at $650 \mathrm{~nm}$ ).

Similar experiments were done by Tang $e t$ al. using free ADPA singlet oxygen probes (34). However, they reported quite different results: $20 \%$ more singlet oxygen was detected for a free-MB sample than for the MB-loaded PAA sample, compared to $150 \%$ in this paper. We believe that this large difference $(20 \%$ vs $150 \%)$ is caused by the diffusion of ADPA into and through the PAA nanoparticles. ADPA is very soluble in water and PAA is very hydrophilic. Thus we believe that ADPA can readily diffuse through the PAA matrix and therefore can have direct contacts with the MB molecules trapped inside, which means that ADPA can detect most of the singlet oxygen released by the MB molecules entrapped inside PAA. Therefore one only observes a minor change when the same amount of MB is incorporated inside PAA.

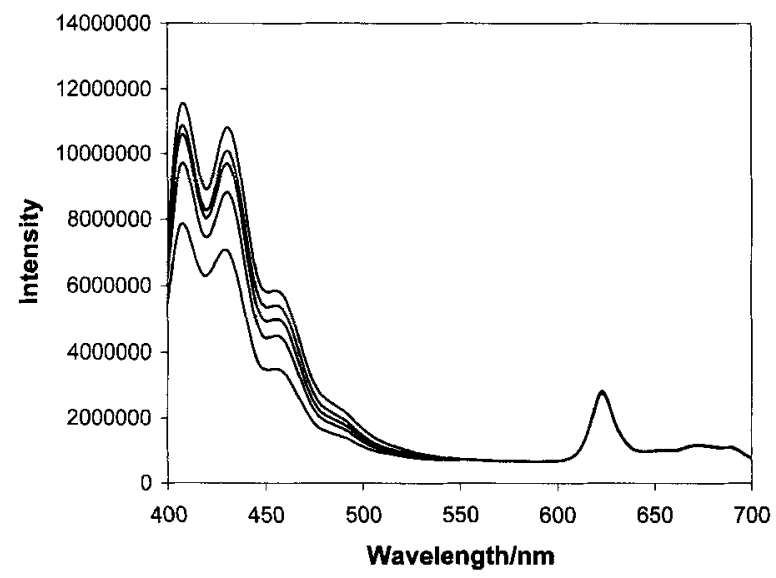

Figure 6. Emission spectra (excited at $380 \mathrm{~nm}$ ) of $1 \mathrm{mg} / \mathrm{mL}$ MBincorporated PAA in distilled water upon light irradiation at $650 \mathrm{~nm}$. The overall concentration of MB is $1 \times 10^{-4} \mathrm{mg} / \mathrm{mL}$ in distilled water. Accumulated irradiation time (from top to bottom): $0 \mathrm{~min}, 1 \mathrm{~min}, 2 \mathrm{~min}, 5 \mathrm{~min}$ and $20 \mathrm{~min}$, respectively.

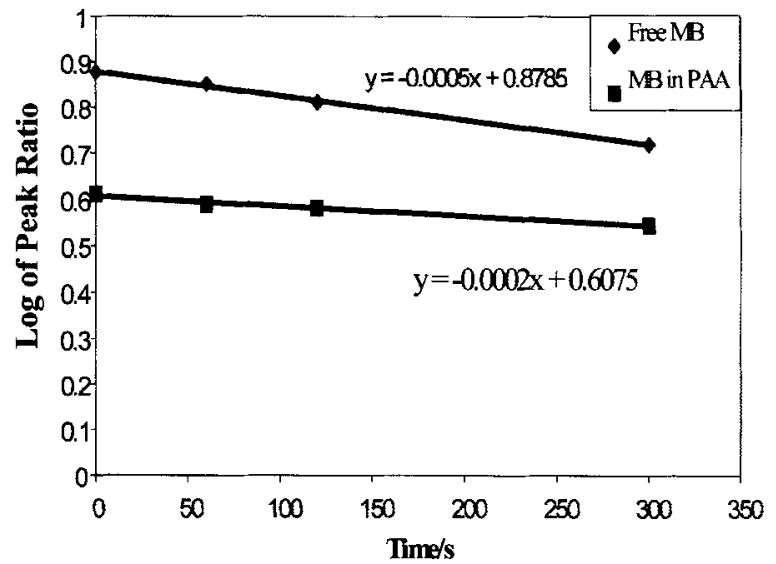

Figure 7. The semilog plot of peak ratio between DMA and OEP against time and the linear fits, used to figure out the $\mathrm{k}$ values for the singlet oxygen detection cases for free MB in water (top line, $R^{2}$ value is 0.997 ) and $\mathrm{MB}$ incorporated inside PAA nanoparticles (bottom line, $R^{2}$ value is 0.988 ).

However, the above described fabricated ratiometric ORMOSIL nanoprobes can only detect the singlet oxygen coming out of the PAA matrix, which is only a small portion of the singlet oxygen produced by MB incorporated inside PAA, upon light illumination. The above comparison provides some evidence that these new ratiometric nanoprobes can differentiate between the singlet oxygen coming out of the nanoparticles and the overall singlet oxygen production. This is extremely important, because in PDT what really matters is the amount of singlet oxygen coming out of the matrix, not the overall production of singlet oxygen. Our lab has been actively developing photosensitizer-loaded nanoplatforms for PDT $(31-33,38)$ and the singlet oxygen nanoprobes described here could become a very useful tool for determining the singlet oxygen production efficiency of the above PDT nanoplatforms.

The conditions of the experimental setups depicted in Figs. 8 and 9 are identical except that, in Fig. 8's setup, the ORMOSIL DMA nanoparticles are used as singlet oxygen probes, whereas in Fig. 9's setup, free ADPA dye probes are used to detect the singlet oxygen. Again, one assumption here is that the concentration of DMA inside ORMOSIL is very close to that of the free ADPA

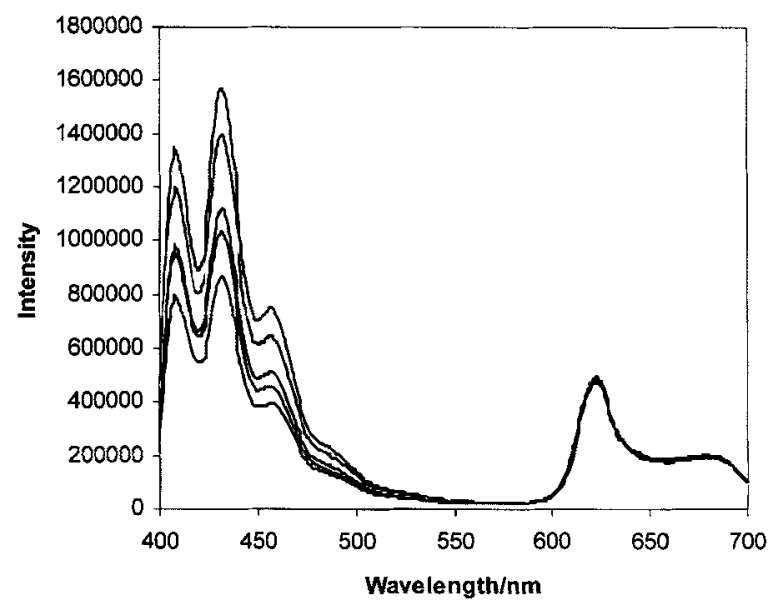

Figure 8. Detection of singlet oxygen produced by amine-functionalized photofrin-incorporated PAA particles via DMA ORMOSIL nanoprobes. Accumulated irradiation time (from top to bottom): $0 \mathrm{~min}, 1 \mathrm{~min}, 5 \mathrm{~min}$, $10 \mathrm{~min}, 20 \mathrm{~min}, 30 \mathrm{~min}$ and $120 \mathrm{~min}$, respectively. 


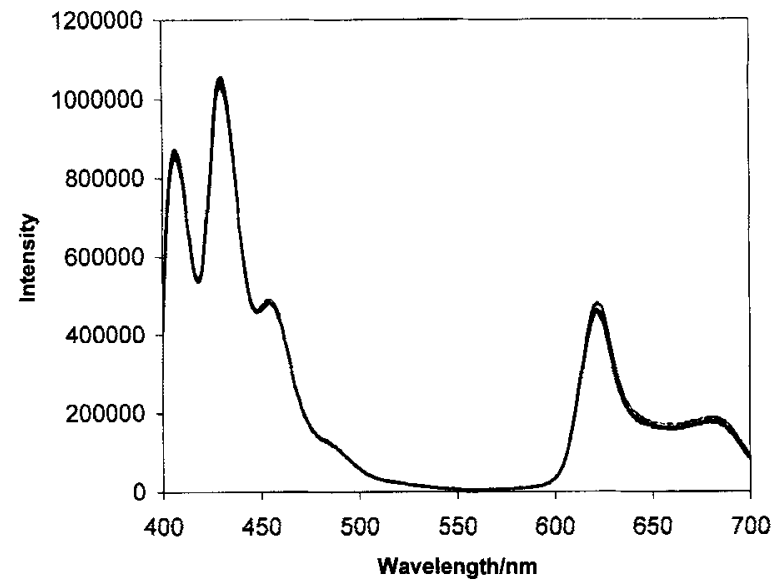

Figure 9. Detection of singlet oxygen produced by amine-functionalized photofrin-incorporated PAA particles via $10 \mu M$ ADPA in water. Accumulated irradiation time (from top to bottom): $0 \mathrm{~min}, 1 \mathrm{~min}, 3 \mathrm{~min}$, $5 \mathrm{~min}, 10 \mathrm{~min}, 20 \mathrm{~min}$ and $30 \mathrm{~min}$, respectively.

probes. This assumption can be roughly justified by the emission intensity comparison of both DMA and ADPA in Figs. 8 and 9.

What is striking, after comparing Figs. 8 and 9, is that the DMA signal decreases about $50 \%$ after 20 min of irradiation at $630 \mathrm{~nm}$, whereas the ADPA's emission stays almost constant during the whole process, which means that almost no singlet oxygen is detected by the ADPA probes in this case.

It should be noted here that the amine-functionalized photofrinloaded PAA particles are more hydrophobic than are ordinary PAA nanoparticles, which is necessary to retain the photofrin molecules; thus it will be very difficult for ADPA molecules to get into the PAA matrix in this scenario. We believe that the much longer lifetime of singlet oxygen inside ORMOSIL, compared with distilled water, singlet oxygen's higher solubility in ORMOSIL than in water and ORMOSIL's high permeability to singlet oxygen, and the higher reaction rate constant (about eight times higher) for DMA, compared to ADPA, play significant roles in explaining this result. The lifetime of singlet oxygen varies significantly from one solvent to another (39). It has also been demonstrated that the lifetime of singlet oxygen in a homogeneous polymer is practically the same as in a liquid solution consisting of analogous molecular structures (1). The lifetime of singlet oxygen in silicone rubber is estimated to be about $51 \mu$ s (1). As

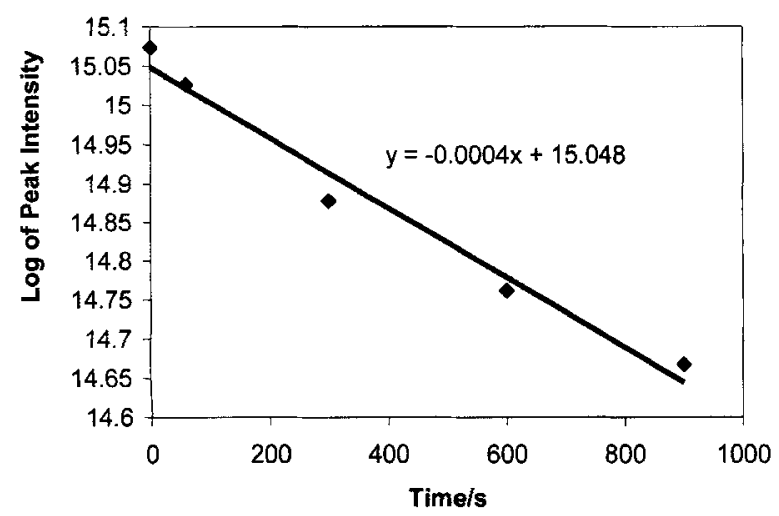

Figure 10. The semilog plot of DMA peak at $432 \mathrm{~nm}$ against time and the linear fit $\left(R^{2}\right.$ value is 0.987$)$ used to figure out the $\mathrm{k}$ value for $0.25 \mathrm{mg} / \mathrm{mL}$ amine-functionalized photofrin-PAA particles in water.

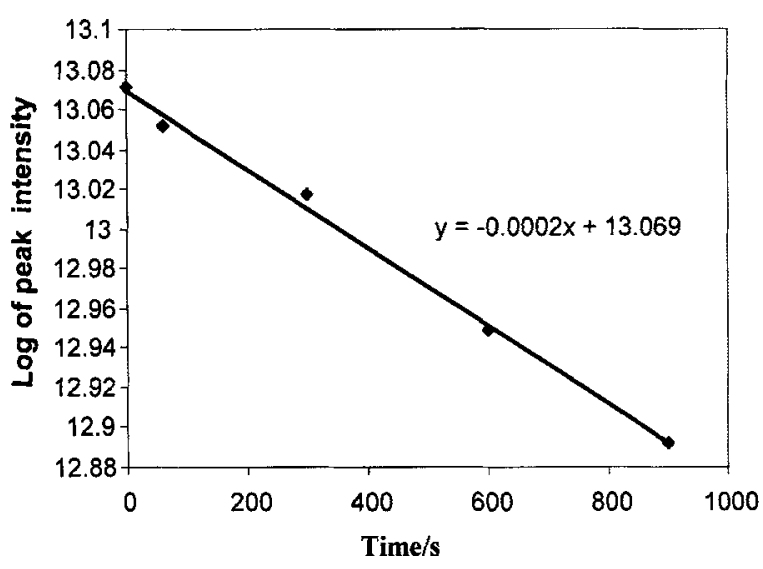

Figure 11. The semilog plot of DMA peak at $432 \mathrm{~nm}$ against time and the linear fit ( $R^{2}$ value is 0.996 ) used to figure out the $\mathrm{k}$ value for $1.0 \mathrm{mg} / \mathrm{mL}$. amine-functionalized photofrin-PAA particles in water.

demonstrated in Scheme 1, the chemical structures of ORMOSIL and silicone rubber are quite similar to each other. Therefore we believe that it is quite reasonable to estimate the lifetime of singlet oxygen in ORMOSIL to be about $50 \mu \mathrm{s}$, which is about 25 times longer than in water. Furthermore, as demonstrated in our previous work (26), ORMOSIL is a very efficient oxygen-permeable polymer with a low diffusion barrier for oxygen, and we believe that the use of ORMOSIL as a matrix favors a scenario in which singlet oxygen molecules will partition in ORMOSIL more than in water and thus will move preferentially into this hydrophobic matrix, out from the aqueous solution and the hydrophilic PAA nanoparticles. Therefore both the relatively longer lifetime of ${ }^{1} \mathrm{O}_{2}$ in ORMOSIL than in water and the higher solubility of ${ }^{1} \mathrm{O}_{2}$ in ORMOSIL than in water significantly enhance these singlet oxygen nanoprobes' sensitivity.

\section{The more photosensitizers, the more singlet oxygen?}

The amount of singlet oxygen produced is dependent upon the type of photosensitizers, the concentration of the photosensitizers, the irradiation light intensity and the nature of the solvents. Also, in many cases it is true that the amount of singlet oxygen produced is proportional to the concentration of the photosensitizers. However in some rare situations, this may not be true, as demonstrated below.

When $100 \mu M \mathrm{MB}$ in water is used as the singlet oxygen source, almost no signal decrease ( $\mathrm{K}$ is almost 0 ) is observed for both ratiometric ORMOSIL nanoprobes and ADPA free-dye probes, even after about $60 \mathrm{~min}$ of irradiation at $650 \mathrm{~nm}$. However, as presented above, the DMA's signal decreases about $73 \%$ after $40 \mathrm{~min}$ of irradiation when $10^{-4} \mathrm{mg} / \mathrm{mL}(0.34 \mu \mathrm{M}) \mathrm{MB}$ in water is used to produce singlet oxygen.

For amine-functionalized photofrin-incorporated PAA particles, as shown in Figs. 10 and 11 , the $\mathrm{K}$ value is $0.0004\left(\mathrm{~S}^{-1}\right)$ for the $0.25 \mathrm{mg} / \mathrm{mL}$ photofrin PAA sample; however it is $0.0002\left(\mathrm{~S}^{-1}\right)$ for a $1.0 \mathrm{mg} / \mathrm{mL}$ sample, which means more singlet oxygen production for a $0.25 \mathrm{mg} / \mathrm{mL}$ sample than for a $1.0 \mathrm{mg} / \mathrm{mL}$ sample after 30 min of irradiation. Again this appears to be counterintuitive.

Therefore, we have observed for both the MB and photofrin samples that higher concentrations of photosensitizers do not necessarily produce more singlet oxygen, but rather the opposite. We believe that this is caused by the fact that the higher concentrations of $\mathrm{MB}$ and photofrin favor the formation of aggregates, e.g. dimers or higher order aggregates, which do not produce singlet oxygen 
upon illumination (40, K. Gwangseong, Y. Cao, Y. E. Koo W. Tang and R. Kopelman, in preparation).

\section{Interference by oxygen and NO}

Experiments have been done to check the interference of oxygen molecules and NO on these ORMOSIL nanoprobes. Our data show that the peak ratios between DMA and OEP are little affected by a continuous flow of oxygen, nitrogen or NO through the aqueous ORMOSIL suspensions.

\section{Leaching}

Leaching is a major concern for PEBBLE nanosensors. The performance, accuracy and lifetime of our nanosensors are directly related to the degree of leaching. Factors such as the molecular size of the dye (smaller molecules more readily leach out through the pores) and the pore size of the matrix (bigger pores favor leaching), and especially the relative solubility of the dyes in the matrix and in water, play very important roles in defining the degree of leaching. In terms of solubility, the solubility of DMA and OEP is much larger in ORMOSIL than in water, as they are hydrophobic and are almost insoluble in water, and this should minimize the leaching. These factors have of course been taken into consideration during the design of these nanosensors. In the tests for leached-out dyes, no leaching could be detected, as none of the spectra taken on these samples show any fluorescence signal being three times higher than the background noise at the emission wavelengths of both dyes entrapped inside the ORMOSIL matrix. This result shows the excellent stability of these ORMOSIL singlet oxygen nanoprobes, in terms of dye leaching, over a period of 3 days.

\section{Photostability}

Our results show that there is almost no emission intensity change for DMA after continuous illumination for $30 \mathrm{~min}$. Thus photobleaching should not be a problem for DMA. The same experiment was carried out for monitoring the emission of OEP, and there is about a $10 \%$ signal decrease after continuous illumination at $380 \mathrm{~nm}$ for $30 \mathrm{~min}$, but only about a $2 \%$ signal decrease after continuous illumination at $650 \mathrm{~nm}$ for $30 \mathrm{~min}$. It should be noted that, during a typical run, using pulsed illumination, the total light exposure time is less than $30 \mathrm{~s}$. Thus, in summary, these ORMOSIL singlet oxygen nanoprobes are sufficiently photostable over their operational time scale.

\section{CONCLUSIONS}

Because most singlet oxygen molecular probes with high reaction rate constants are hydrophobic, they have been conventionally modified through synthesis to be hydrophilic (such as ADPA) so that they could be used for singlet oxygen detection in aqueous solutions or biological environments. However, the performance of these modified naked molecular probes is often limited by the relatively short lifetime and poor solubility of ${ }^{1} \mathrm{O}_{2}$ in aqueous solutions, in addition to the possible dye toxicity problem. In this paper, the highly sensitive singlet oxygen molecular DMA probes are encapsulated inside ORMOSIL polymer matrix, thus making the detection of ${ }^{1} \mathrm{O}_{2}$ take place inside ORMOSIL. This approach has demonstrated significant advantages over the naked dye probes such as ADPA, and we believe that this is because of the following conditions: (1) the much longer lifetime of singlet oxygen inside the ORMOSIL matrix than in water; (2) singlet oxygen's higher solubility in ORMOSIL than in water and ORMOSIL's high permeability to singlet oxygen; and (3) the protection of the dyes by the matrix. Therefore, the introduction of ORMOSIL as the matrix not only protects the dye molecules from direct contact with the outside environment but also significantly enhances its sensitivity to singlet oxygen. These nano-PEBBLE probes appear to be the first ratiometric singlet oxygen nanoprobes ever developed. These nanoprobes have been used to monitor the singlet oxygen production by photosensitizer-loaded PDT nanoplatforms, with significant success, and they have revealed the dimmer- or higher-order aggregation effects of the PDT platforms. Another unique feature about these nanoprobes is that they only detect the singlet oxygen coming out of the photodynamic nanoplatforms, which is critical in determining the singlet oxygen production efficiency of the nanoplatforms. Thus these new nanoprobes could become ideal tools for quality control in PDT, for both qualitative and quantitative analysis and monitoring. Because of their high sensitivity (resulting from a combination of the highly sensitive DMA dye molecules with the more favorable singlet oxygen detection environment inside the ORMOSIL matrix) as well as their good biocompatibility, these nanoprobes are quite promising for intracellular singlet oxygen detection.

Acknowledgements--This work was sponsored by $\mathrm{NIH} / \mathrm{NCI}$ contract N01-CO-07013 and by NIH grant EB00250. We also thank the University of Michigan Electron Microbeam Analysis Laboratory for use of the TEM and SEM.

\section{REFERENCES}

1. Schweitzer, C. and R. Schmidt (2003) Physical mechanisms of generation and deactivation of singlet oxygen. Chem. Rev. 103, 1685-1757.

2. Krinsky, N. I. (1979) Biological roles of singlet oxygen. In Singlet Oxygen, Vol. 40 (Edited by H. H. Wasserman), pp. 597-641, Academic Press, New York.

3. Steinbeck, M. J., A. U. Khan and M. J. Karnovsky (1992) Intracellular singlet oxygen generation by phagocytosing neutrophils in response to particles coated with a chemical trap. J. Biol. Chem. 267(19), $13425-13433$.

4. Kanofsky, J. R., H. Hoogland, R. Wever and S. J. Weiss (1998) Singlet oxygen production by human eosinophils. J. Biol. Chem. 263(20), 9692-9696.

5. Ryter, S. W. and R. M. Tyrrell (1998) Singlet molecular oxygen ${ }^{1} \mathrm{O}_{2}$ : a possible effector of eukaryotic gene expression. Free Rad. Biol. Med. 24(9), 1520-1534

6. Prein, M. and W. Adam (1996) The Schenck Ene reaction: diastereoselective oxyfunctionalization with singlet oxygen in synthetic applications. Angew. Chem. Int. editor. Engl. 35, 477-494.

7. Henderson, B. W. and T. J. Dougherty (1992), How does photodynamic therapy work? Photochem. Photobiol. 55, 145-157.

8. Levy, J. G. and M. Obochi (1996) New applications in photodynamic therapy. Photochem. Photobiol. 64, 737-739.

9. Dougherty, T. J., C. J. Gomer, B. W. Henderson, G. Jori, D. Kessel, M. Korbelik, J. Moan and Q. Peng (1998) Review: photodynamic therapy. J. Nat. Cancer Inst. 90, 889-905.

10. Fuchs, J. and J. Thiele (1998) The role of oxygen in cutaneous photodynamic therapy. Free Rad. Biol. Med. 24, 835-847.

11. Oleinick, N. L. and H. H. Evans (1998) The photobiology of photodynamic therapy: cellular targets and mechanisms. Radiat. Res. 150, S146-S156.

12. Popovic, E. A., A. H. Kaye and J. S. Hill (1996) Photodynamic therapy of brain tumors. J. Clin. Laser Med. Surg. 14, 251-261.

13. Weishaupt, K. R., C. J. Gomer and T. J. Dougherty (1976) Identification of singlet oxygen as the cytotoxic agent in photoinactivation of a marine tumor. Cancer Res. 36, 2326-2329.

14. Baker, A. and J. R. Kanofsky (1992) Quenching of singlet oxygen by biomolecules from L1210 leukemia cells. Photochem. Photobiol. 55, 523-528. 
15. Skovsen, E., J. W. Snyder, J. Lambert and P. R. Ogilby (2005) Lifetime and diffusion of singlet oxygen in a cell. Phys. Chem. B 109, $8570-8573$

16. Baker, A. and J. R. Kanofsky (1991) Direct observation of singlet oxygen phosphorescence at $1270 \mathrm{~nm}$ from L1210 leukemia cells exposed to polyporphyrin and light. Arch. Biochem. Biophys. 186, 70-75.

17. Baker, A. and J. R. Kanofsky (1993) Time-resolved studies of singletoxygen emission from L1210 leukemia cells labeled with 5-(nhexadecanoyl) amino eosin: a comparison with a one dimensional model of singlet oxygen diffusion and quenching. Photochem. Photobiol. 57, 720-727.

18. Oelckers, S., T. Ziegler, I. Michler and B. Roder (1999) Time resolved detection of singlet oxygen luminescence in red-cell ghost suspensions: concerning a signal component that can be attributed to ${ }^{1} \mathrm{O}_{2}$ luminescence from the inside of a native membrane. J. Photochem. Photobiol. B 53, 121-127.

19. Niedre, M., M. S. Patterson and B. C. Wilson (2002) Direct nearinfrared luminescence detection of singlet oxygen generated by photodynamic therapy in cells in vitro and tissues in vivo. Photochem. Photobiol. 75, 382-391.

20. Lindig, B. A., A. J. Rodgers, and A. P. Schaap (1980) Determination of the lifetime of singlet oxygen in water-d2 using 9,10-anthracenedipropionic acid, a water-soluble probe. J. Am. Chem. Soc. 102, 5590-5593.

21. Castellano, F. N. and J. R. Lakowicz (1998) A water-soluble luminescence oxygen sensor. Photochem. Photobiol. 67, 179-183.

22. Umezawa, N., K. Tanaka, Y. Urano, K. Kikuchi, T. Higuchi and T. Nagano (1999) Novel fluorescent probes for singlet oxygen. Angew. Chem. Int. editor. 38, 2899-2901.

23. Drews, W., R. Schmidt and H. D. Brauer (1980) The photolysis of the endoperoxide of 9,10-diphenylanthracene. Chem. Phys. Lett. 70, 84-88.

24. Clark, H., S. M. Barker, M. Brasuel, M. Miller, E. Monson, S. Parus, Z. Y. Shi, A. Song, B. Thorsrud, R. Kopelman, A. Ade, W. Meixner, B. Athey, M. Hoyer, D. Hill, R. Lightle and M. A. Philbert (1998) Subcellular optochemical nanobiosensors: probes encapsulated by biologically localized embedding (PEBBLE). Sens. Acuators, B 51, $12-16$.

25. Monson, E., M. Brasuel, M. Philbert and R. Kopelman (2003) Chapter 59. PEBBLE Nanosensors for in vitro bioanalysis. In Biomedical Photonics Handbook (Edited by T. Vo-Dinh), pp. 59-1-59-14. CRC Press, Boca Raton, FL

26. Koo, Y., Y. F. Cao, R. Kopelman, S. M. Koo, M. Brasuel and M. A. Philbert (2004) Real-time measurements of dissolved oxygen inside live cells by Ormosil (organically modified silicate) fluorescent PEBBLE nanosensors. Anal. Chem. 76, 2498-2505.

27. Tanaka, T., N. Miura, N. Umezawa, Y. Urano, K. Kikuchi, T. Higuchi and T. Nagano (2001) rational design of fluorescein-based fluorescence probes. Mechanism-based design of a maximum fluorescence probe for singlet oxygen. J. Am. Chem. Soc. 123, 2530-2536.
28. Turro, N. J., M. F. Chow and J. Rigaudy (1979) Thermolysis of anthracene endoperoxides. concerted vs. diradical mechanisms, microscopic reversibility in endothermic chemiluminescent reactions. J. Am. Chem. Soc. 94, 7244-7255.

29. Steinbeck, M. J., A. U. Khan and M. J. Karnovsky (1993) Extracellular production of singlet oxygen by stimulated macrophages quantified using 9, 10-diphenylanthracene and perylene in a polystyrene film. J. Biol. Chem. 268(21), 15649-15654.

30. Moreno, M. J., E. Monson, R. G. Reddy, A. Rehemtulla, B. D. Ross, M. Philbert, R. J. Schneider and R. Kopelman (2003) Production of singlet oxygen by $\mathrm{Ru}\left(\mathrm{dpp}\left(\mathrm{SO}_{3}\right)_{2}\right)_{3}$ incorporated in polyacrylamide PEBBLE. Sens. Actuators, B: Chemical 90, 82-89.

31. Ross, B., A. Rehemtulla, Y. E. Koo, R. Reddy, G. Kim, C. Behrend, S. Buck, R. J. Schneider II, M. A. Philbert, R. Weissleder and R. Kopelman (2004) Photonic and magnetic nanoexplorers for biomedical use: from subcellular imaging to cancer diagnostics and therapy. SPIE (International Society of Photonic Engineering) 5331, 76-83.

32. Kopelman, R., Y. E. Koo, M. Philbert, B. A. Moffat, G. R. Reddy, P. McConville, D. E. Hall, T. L. Chenevert, M. S. Bhojani, S. M. Buck, A. Rehemtulla and B. D. Ross (2005) Multifunctional nanoparticle platforms for in-vivo MRI enhancement and photodynamic therapy of a rat brain cancer. J. Magnetism Magnetic Materials 293 404-410.

33. Xu, H., S. M. Buck, R. Kopelman, M. A. Philbert, M. Brasuel, B. Ross, A. Rehemtulla and J. Festschrift (2004) Photo-excitation based nanoexplorers: chemical analysis inside live cells and photodynamic therapy. Israel J. of Chem. 44, 317-337.

34. Tang, W., H. Xu, M. Philbert and R. Kopelman (2005) Photodynamic characterization and in vitro application of $\mathrm{MB}$-containing nanoparticle platforms. Photochem. Photobiol. 81(2), 242-249.

35. Derossa, M. C. and R. J. Crutchley (2002) Photosensitized singlet oxygen and its applications. Coord. Chem. 233, 351-372.

36. Aubry, J. M., C. Pierlot, J. Rigaudy and R. Schmidt (2003) Reversible binding of oxygen to aromatic compounds. Acc. Chem. Res. 36 668-675.

37. Notre Dame Radiation Laboratory (2005) NDRL radiation chemistry data center. Available at: http://www.rcdc.nd.edu/index.html. Accessed 5 October 2005

38. Yan, F, and R. Kopelman (2003) The embedding of metatetra(hydroxyphenyl)-chlorin into silica nanoparticle platforms for photodynamic therapy and their singlet oxygen production and $\mathrm{pH}$ dependent optical properties. Photochem. Photobiol. 78, 587-591.

39. Jenny, T. and N. Turro (1982) Solvent and deuterium isotope effects on the lifetime of singlet oxygen determined by direct emission spectroscopy at $1.27 \mu \mathrm{m}$. Tetrahedron Letters 23, 2923-2926.

40. Tanielian, C., C. Schweitzer, R. Mechin and C. Wolff (2001) Quantum yield of singlet oxygen production by monomeric and aggregated forms of hematoporphyrin derivative. Free Rad. Biol. Med. 30(2), 208-212. 